\title{
Effect of Fuel Injection and Mixing Characteristics on Pulse-Combustor Performance at High-Pressure
}

\author{
Shaye Yungster ${ }^{1}$ \\ Ohio Aerospace Institute, Cleveland, OH 44142 \\ Daniel E. Paxson ${ }^{2}$ and Hugh D. Perkins ${ }^{3}$ \\ NASA Glenn Research Center, Cleveland, OH 44135
}

\begin{abstract}
Recent calculations of pulse-combustors operating at high-pressure conditions produced pressure gains significantly lower than those observed experimentally and computationally at atmospheric conditions. The factors limiting the pressure-gain at high-pressure conditions are identified, and the effects of fuel injection and air mixing characteristics on performance are investigated. New pulse-combustor configurations were developed, and the results show that by suitable changes to the combustor geometry, fuel injection scheme and valve dynamics the performance of the pulse-combustor operating at high-pressure conditions can be increased to levels comparable to those observed at atmospheric conditions. In addition, the new configurations can significantly reduce the levels of NOx emissions. One particular configuration resulted in extremely low levels of NO, producing an emission index much less than one, although at a lower pressure-gain. Calculations at representative cruise conditions demonstrated that pulse-combustors can achieve a high level of performance at such conditions.
\end{abstract}

\section{Nomenclature}

$=$ emission index (grams of NO per kilogram of fuel)

$=$ pulse combustor operating frequency

$=$ pulse combustor length

$=$ total massflow rate

$=$ pressure

$=$ inlet total pressure

$=$ average combustor pressure

$=$ fuel injection pressure

$=$ peak combustor pressure

$=$ temperature

$=$ inlet total temperature

$=$ time

$=$ end of fuel injection time

$=$ start of fuel injection time

$=$ start of valve closing time

$=$ start of valve opening time

$=$ valve fully closed time

$=$ valve fully open time

$=$ axial coordinate

$=$ equivalence ratio

\footnotetext{
${ }^{1}$ Senior Scientist, Senior AIAA Member.

${ }^{2}$ Aerospace Engineer, Associate Fellow AIAA.

${ }^{3}$ Aerospace Engineer, AIAA Member.
}

American Institute of Aeronautics and Astronautics 


\section{Introduction}

Pulse-combustors are unsteady, resonant thermo-acoustic devices in which heat released by combustion is coupled with the acoustic field. When used in combination with ejector systems, pulse-combustors have several advantages over alternative pressure gain combustion concepts. By being relatively simple devices, pulsecombustors avoid the mechanical complexities of higher pressure gain concepts such as wave rotors and detonationbased devices. Flow non-uniformities at the exit of these pulse-combustor devices have been shown to be substantially lower in comparison to those observed in detonation-based devices ${ }^{1}$. This smoothing aspect of pulsecombustor-based systems is critical for maintaining high turbomachinery performance. In addition, the emissions of oxides of nitrogen in pulse-combustors are potentially lower than in conventional combustor systems ${ }^{2}$.

Most previous studies of pulse-combustors have been carried out at atmospheric conditions ${ }^{3-5}$. However, practical aerospace applications of pressure-gain combustion systems necessitates operation at high-pressure conditions. Recently, we presented an initial study ${ }^{6}$ that analyzed the differences in the operation of pulsecombustors at atmospheric $\left(p_{0}=1 \mathrm{bar} ; T_{0}=298 \mathrm{~K}\right)$ and high-pressure conditions $\left(p_{0}=10 \mathrm{bar} ; T_{0}=550 \mathrm{~K}\right)$. The results showed that the higher air temperature, and to a lesser extent, the higher pressure resulted in faster kinetics which significantly affected the combustion process, and increased the operating frequency of the pulse-combustor. This effect necessitated valving of the fuel and delaying the fuel injection process in order to prevent pre-ignition of the reactants entering the combustor. However, the amplitude of the pressure oscillations and the average combustor pressure at the high-pressure conditions was lower than that typically observed during operation at atmospheric conditions.

Figure 1 compares the pressure variation in the pulse combustor as a function of time for the atmospheric and high-pressure cases. Figure 1a shows experimental and computational head-end pressure ratio variation with time at atmospheric conditions, originally presented in Ref. 6. The computed amplitude of the pressure oscillations was in reasonable agreement with experiments, but the computed frequency of oscillation was approximately $10 \%$. higher. The differences were attributed mainly to the different fuels used in the experiment (liquid gasoline) and the numerical simulations (gaseous jet-A). Although liquid and gaseous fuels behave radically different, the fundamental features of pulse-combustor operation were successfully reproduced using a gaseous fuel model.

Figure $1 \mathrm{~b}$ shows typical computed pressures, obtained in Ref. 6, for a pulse-combustor operating at highpressure conditions. Results are presented for two equivalence ratios $(\Phi=0.7$, and $\Phi=1.1)$. Alternating colors are used in this and subsequent figures to differentiate each cycle.

Lower pressure gains were consistently obtained in our previous study during high-pressure operation, compared with operation at atmospheric conditions.

The objective of the present study is to understand the reasons behind the lower performance, by investigating computationally the effects of fuel injection and air mixing characteristics on pulse combustor operation at highpressure conditions. The goal is to design new configurations able to achieve pressure gains at high-pressure conditions commensurate to those observed at atmospheric conditions. In addition, the new pulse-combustor configurations must also maintain acceptable levels of NOx emissions.

(a)

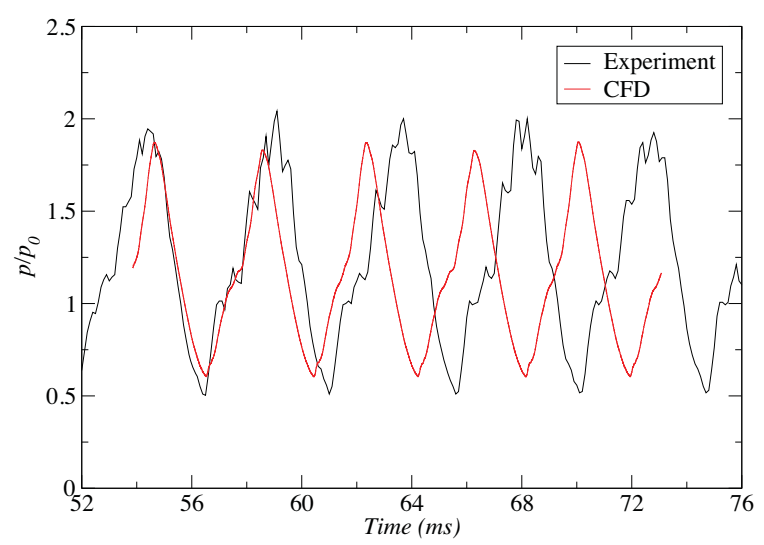

(b)

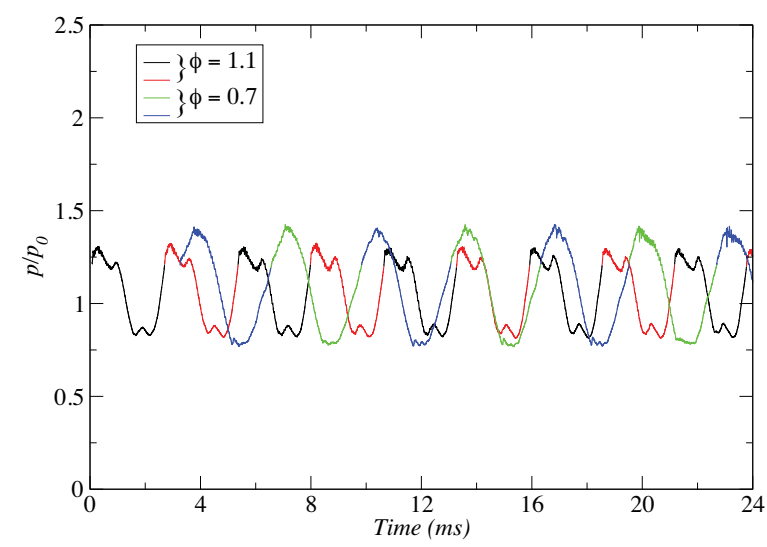

Figure 1. Pulse-combustor pressure vs time for (a) atmospheric conditions ( $\left(p_{0}=1\right.$ bar, $\left.T_{0}=298 \mathrm{~K}\right)$ (b) high-pressure conditions ( $p_{0}=10 \mathrm{bar}, T_{0}=550 \mathrm{~K}$ ). 


\section{Computational Model}

The baseline pulse-combustor considered in this and our previous study ${ }^{6}$ is based on an experimental device investigated at the NASA Glenn Research Center ${ }^{1}$. Figure 2 shows a schematic of the experimental pulse-combustor and the axisymmetric computational model. The reed valve is the only moving part in the pulse-combustor. Its position is determined at every instant by the pressure differential existing between the inlet and combustor sides. In the present study we use the same vertically sliding valve model used in our previous work ${ }^{6}$ to approximate the reed valve action. This valve model removes the need to compute a special boundary condition at the combustor/inlet interface that has been used in previous studies ${ }^{2,3}$. The combustor/inlet interface becomes an interior domain in the CFD calculation, and a specified total pressure and total temperature boundary condition is applied upstream, at the inlet entrance. Opening and closing of the valve is determined by the pressure at the head-end of the pulsecombustor, and the motion of the valve as a function of time is specified by an exponential function.

The numerical simulations of the pulse-combustor are carried out using a Computational Fluid Dynamics (CFD) code developed in-house ${ }^{7,8}$. The analysis is based on the axisymmetric, unsteady, Reynolds-averaged Navier-Stokes equations for a multi-species, thermally perfect, chemically reacting gas. The turbulence model used in the calculations is the Spalart-Allmaras one-equation model ${ }^{9}$. Adiabatic walls were assumed for all cases considered, and the grid had a minimum wall spacing of $1 \times 10^{-3}$ in (resulting in values for $\mathrm{y}^{+}$of order one).

The numerical method used for solving the governing equations is described in detail in Refs. 7 and 8 . Briefly stated, the equation set is solved using a fully implicit, variable-step backward differentiation formula (BDF) method. In this research, the temporally first order backward Euler version of the scheme was utilized. The numerical fluxes are evaluated using a second-order spatially accurate total variation diminishing (TVD) scheme. The resulting equations are then linearized in a conservative manner and solved iteratively, by using a lower-upper relaxation procedure consisting of successive Gauss-Seidel (LU-SGS) sweeps.

The fuel considered in this study is gaseous Jet-A, which is modeled as a $\mathrm{C}_{11} \mathrm{H}_{21}$ species. A reduced combustion mechanism, based on the model developed by Ajmani et al. ${ }^{10,11}$, consisting of 10 elementary reactions among 11

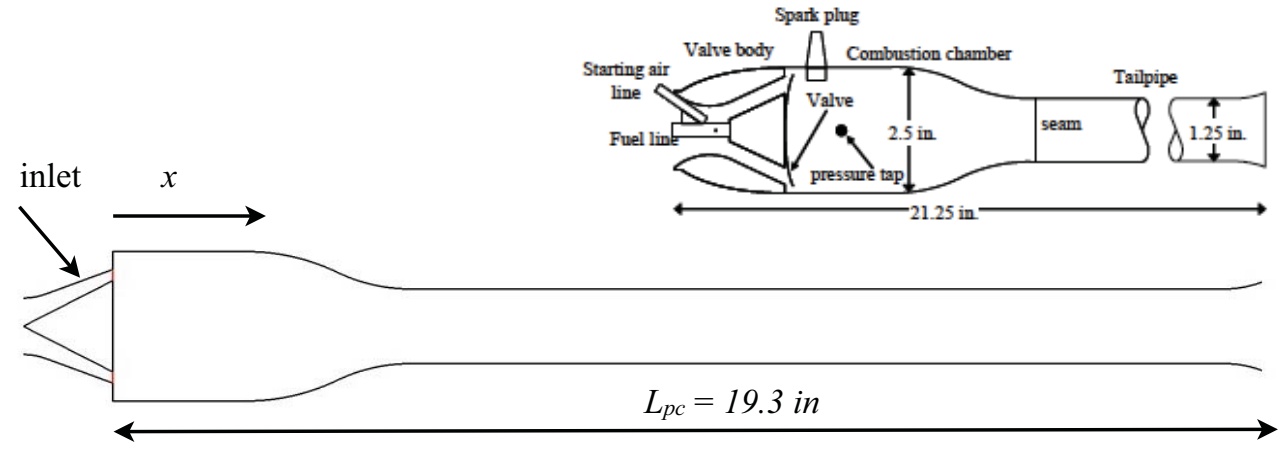

Figure 2. (a) Schematic of experimental pulse-combustor; (b) baseline computational model.

reacting species was utilized. An additional four NO reactions, taken from Jachimowski's hydrogen-air combustion model $^{12}$ were added to this model. The complete reaction mechanism is given in the Appendix. Reactions 11-14 represent the extended Zeldovich mechanism for thermal NO production. This NOx mechanism has also been successfully used in previous studies of pulse detonation engines. ${ }^{13,14}$

\section{Pulse-Combustor Operation}

The pulse-combustor cycle (also known as a "pulsejet" cycle) was described in detail in Ref. 6. Briefly stated, It consists of three main phases:

I) The heat release phase, in which the combustion process raises the pressure and temperature in the combustor and generates a series of compression waves that propagate downstream. When these compression waves reach the end of the pulse-combustor, they are reflected as expansion waves.

II) The blowdown phase, during which the combustion products exit the pulse-combustor, and the pressure and temperature in the combustor decreases.

III) The recharge phase, during which the opening of the valve allows a fresh charge of fuel and air to enter the combustor. The flow of fresh reactants forms a toroidal vortex in the combustor forcing mixing of air, fuel and combustion products. After a period of time dictated by the mixing and ignition delay times, a new combustion 
front is formed, the valve closes (due to the increased pressure), and the cycle repeats. The performance of the pulsejet is maximized when the heat release is synchronized with the arrival of the reflected compression wave system, approximating a constant volume combustion process.

\section{Pulse-Combustor Simulations}

All the numerical simulations presented here were run for multiple cycles until the overall flowfield approached periodicity (limit cycle). This typically required 8-12 cycles. This computational model permits the study of various configurations in multi-cycle mode within reasonable computational times. A typical case (170000 grid points) required 16 hours of wall-time per cycle using 24 processors on the NAS supercomputer "Endeavour".

All the cases presented in the sections 4.1 and 4.2 assume a total pressure of $p_{0}=10$ bar and total temperature of $T_{0}=550 \mathrm{~K}$ boundary condition applied at the inlet inflow plane. The last section (4.3) examined performance at cruise conditions $\left(p_{0}=13.2\right.$ bar and $\left.T_{0}=750 \mathrm{~K}\right)$.

\section{(4.1) Simulations with the modified pulse-combustor}

The first step towards improving the performance of the pulse-combustor at high-pressure conditions was to improve the aerodynamic efficiency of the baseline combustor design by providing a smoother airflow passage and removing the sharp corner, where unburnt fuel tended to accumulate. The modified combustor is shown in Fig. 3. This figure also shows the computational domain and temperature contours (for $\Phi=0.66$ ) at the start of the cycle. In all the computations, the inflow planes for the pulse-combustor inlet and external domain were treated as subsonic inflow boundaries where the total pressure $\left(p_{0}\right)$ and total temperature $\left(T_{0}\right)$ were specified. The other boundaries were treated as subsonic outflow boundaries where the static pressure was imposed. In this study, the static pressure was set equal to the total pressure $p_{0}$. Fuel is injected through discrete injectors, as described later in the paper.

Figures 4 and 5 compare the results obtained with the baseline and modified combustors. A summary of some of the key parameters associated with these and all other cases presented in this paper are given in Table 1. Details of the fuel injection and valve timing events are given in Table 2.

Figures 4 and 5 show temperature contours (top half) and fuel mass fraction contours (bottom half) during one cycle. Referring to Fig. 4a, combustion is seen occurring mainly at the external edge of the vortex, with some combustion also occurring inside the vortex core. The two flame fronts then propagate around the edge of the vortex, merging together (Fig. $4 \mathrm{~b}$ ) and eventually consuming most of the fuel (Fig. 4c). At $\mathrm{t}=1.39 \mathrm{~ms}$ the valve begins to open (Fig. $4 \mathrm{~d}$ shows the valve partially open) and at $t=2.24 \mathrm{~ms}$ the fuel injection process starts (Fig. $4 \mathrm{e}$, 4f). The ignition of the reactants can be observed in Fig. $4 \mathrm{~g}$ near the upper right edge of the vortex while the valve has already started to close. At $t=3.07 \mathrm{~ms}$ the valve is fully closed (Fig. $4 \mathrm{~h}$ ) and the cycle repeats. The combustion process for the modified combustor, shown in Fig.5, is very similar, except that in this case the vortex stretches out further into the combustor, and combustion occurs exclusively at the external edge of the vortex. Note that the accumulation of fuel in the corner of the baseline combustor (Figs 4f-4h) is not present in the modified combustor.

The pressure at the head-end of the combustor, for both the baseline and the modified combustor, is plotted in Fig. 6. The peak pressure ratio and the average combustor pressure ratio, given in Table 1, are similar in both cases. Both are lower than that obtained at atmospheric conditions (given also in Table 1). The frequency of operation with the modified combustor was slightly higher than that for the baseline combustor ( $334 \mathrm{~Hz} v 324 \mathrm{~Hz}$ ). For comparison, the computed operating frequency at atmospheric conditions was $269 \mathrm{~Hz}$. The higher air temperature,

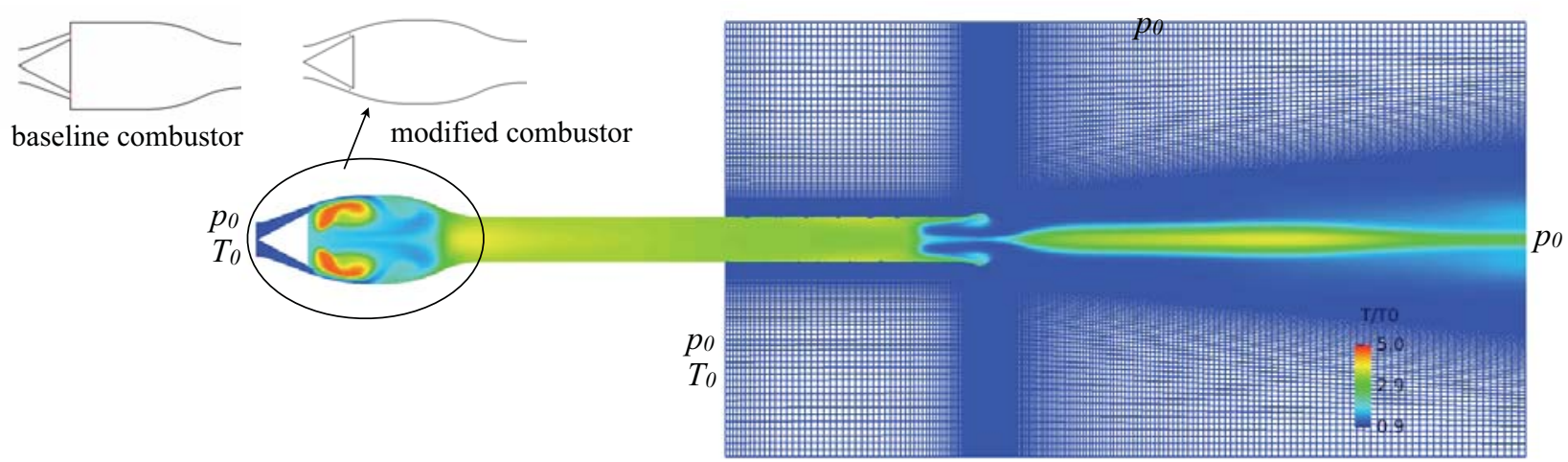

Figure 3. Schematic of modified pulse combustor and axisymmetric computational domain.

American Institute of Aeronautics and Astronautics 


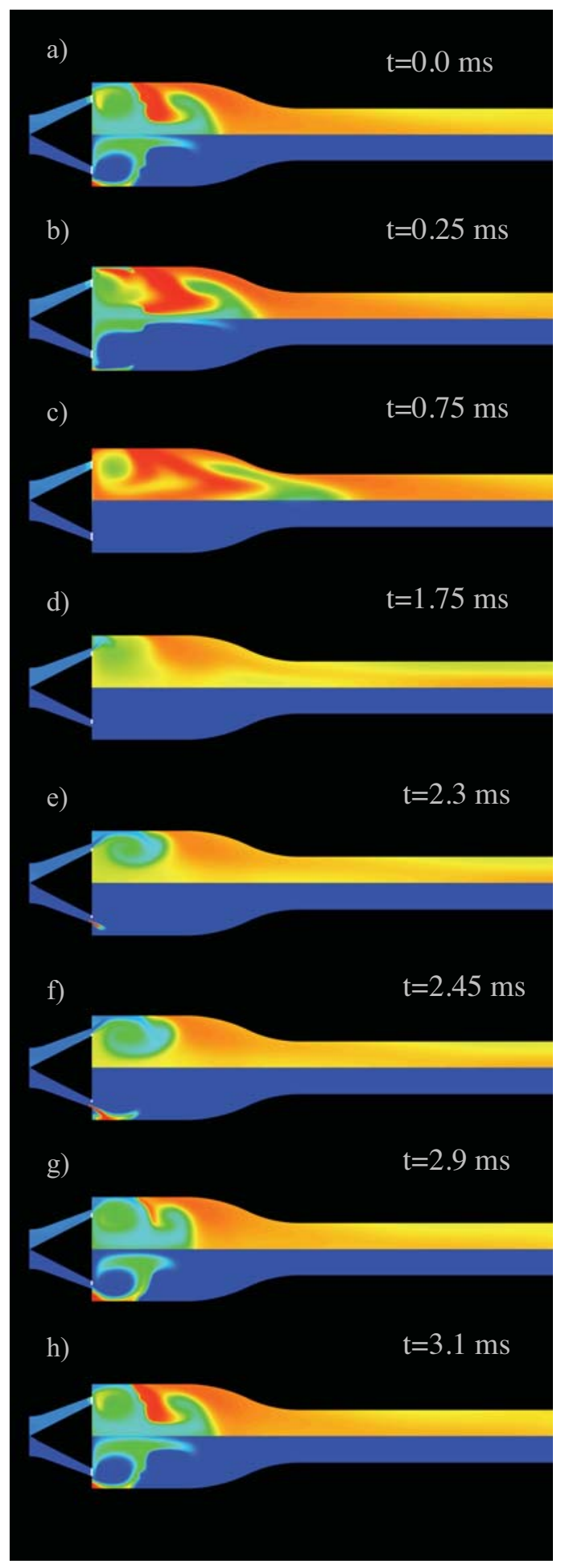

Figure 4. Nondimensional temperature contours (top half) and fuel mass fraction contours (bottom half) at various times during one cycle ( $p_{0}=10 \mathrm{bar}, T_{0}=550 \mathrm{~K}$, $\Phi=0.7$ ). Baseline combustor and original valve dynamics.

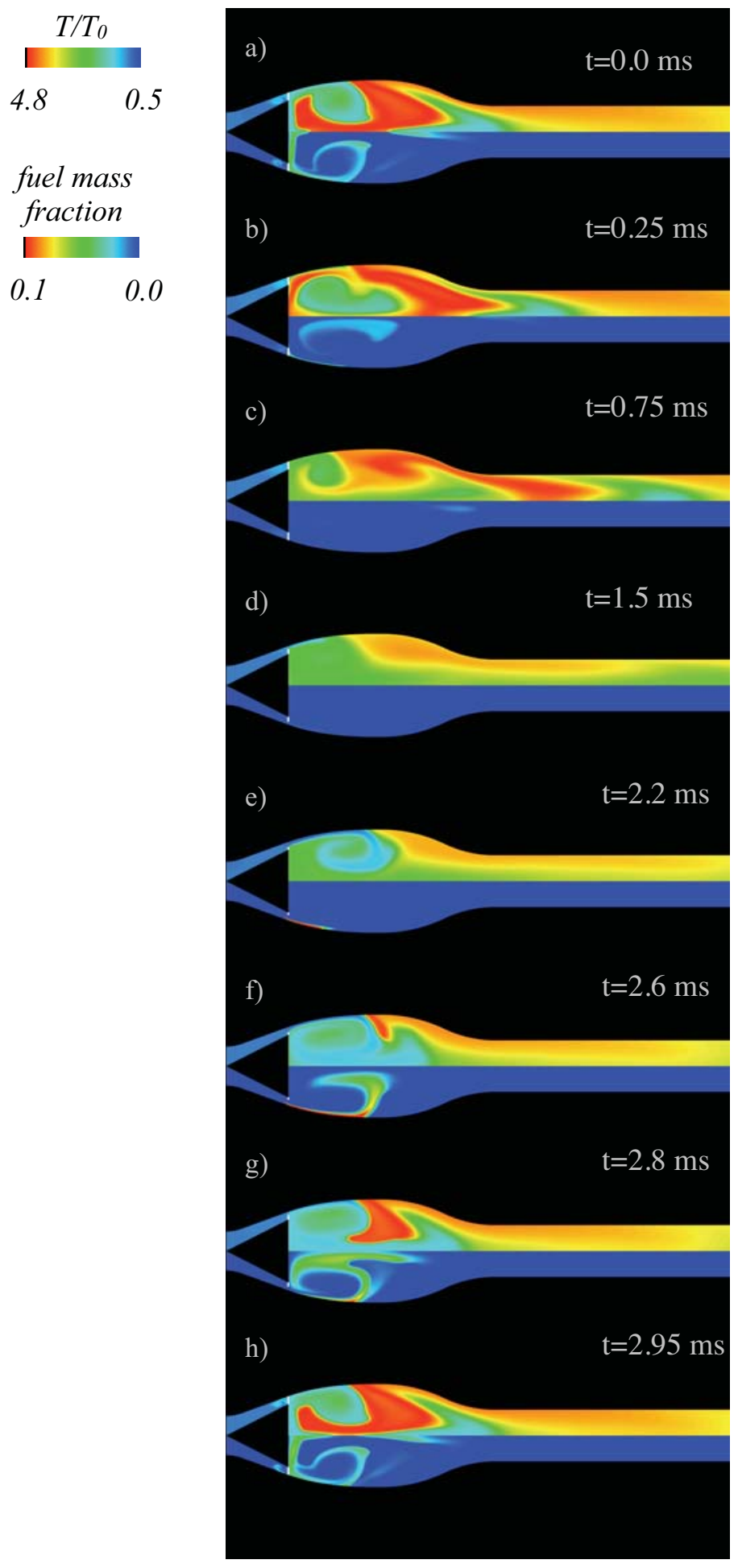

Figure 5. Nondimensional temperature contours (top half) and fuel mass fraction contours (bottom half) at various times during one cycle ( $p_{0}=10 \mathrm{bar}, T_{0}=550 \mathrm{~K}$, $\Phi=0.65)$. Modified combustor and original valve dynamics. 


\begin{tabular}{|c|c|c|c|c|c|c|c|c|c|c|}
\hline \multicolumn{10}{|c|}{ Table 1. Summary of Pulse-Combustor Simulations } \\
\hline $\begin{array}{c}\text { combustor } \\
\text { type }\end{array}$ & $\begin{array}{c}\text { valve } \\
\text { dynamics }\end{array}$ & figure & $\begin{array}{c}\mathrm{p}_{0} \\
(\mathrm{bar})\end{array}$ & $\begin{array}{c}\mathrm{T}_{0} \\
(\mathrm{~K})\end{array}$ & $\begin{array}{c}\mathrm{p}_{\text {inj }} \\
(\mathrm{bar})\end{array}$ & $\begin{array}{c}\mathrm{f} \\
(\mathrm{Hz})\end{array}$ & $\Phi$ & $\mathrm{p}_{\max } / \mathrm{p}_{0}$ & $\mathrm{p}_{\text {avg }} / \mathrm{p}_{0}$ & $\begin{array}{c}\dot{m}_{T} \\
(\mathrm{Kg} / \mathrm{s})\end{array}$ \\
\hline baseline & original & Fig.1 & 1.0 & 298 & 1.0 & 269 & 2.70 & 1.87 & 1.158 & 0.0253 \\
\hline baseline & original & Fig. 4 & 10.0 & 550 & 10.0 & 325 & 0.70 & 1.45 & 1.064 & 0.095 \\
\hline modified & original & Fig. 5 & 10.0 & 550 & 10.5 & 334 & 0.65 & 1.42 & 1.064 & 0.128 \\
\hline modified & reverse & Fig. 8 & 10.0 & 550 & 10.0 & 327 & 0.66 & 1.83 & 1.088 & 0.219 \\
\hline modified & reverse & Fig. 12 & 10.0 & 550 & 10.3 & 337 & 0.72 & 2.01 & 1.114 & 0.247 \\
\hline modified & reverse & Fig. 12 & 10.0 & 550 & 10.5 & 345 & 0.78 & 2.26 & 1.135 & 0.235 \\
\hline baseline & reverse & Fig. 13 & 10.0 & 550 & 10.0 & 292 & 0.57 & 1.51 & 1.052 & 0.220 \\
\hline baseline & reverse & Fig. 14 & 10.0 & 550 & 10.3 & 319 & 0.64 & 1.76 & 1.086 & 0.228 \\
\hline modified & reverse & Fig. 15 & 13.2 & 745 & 12.8 & 362 & 0.60 & 1.97 & 1.082 & 0.291 \\
\hline
\end{tabular}

and to a lesser extent, the higher pressure results in faster kinetics and a higher frequency of operation at the highpressure condition.

The geometric modification improved the aerodynamic characteristic of the pulse-combustor flow, but was not sufficient to achieve the type of pressure gain observed at atmospheric conditions (Fig. 1a).

Two factors appear to be limiting the pressure-gain at the high-pressure conditions. The first one is related to the fact that for both the baseline and the modified combustors, the combustion front at high-pressure conditions occurs mainly at the external edge of the vortex. In contrast, the combustion front for the atmospheric case was mostly constrained to the interior of the vortex (see ref. 6). This type of combustion mode appears to be more efficient in coupling with the acoustic field of the pulse-combustor. The second factor is related to the massflow rate through the combustor. Increasing the pressure by a factor of ten, would normally be accompanied by a corresponding increase in the massflow rate. However, because in this case the air temperature has also increased (from $298 \mathrm{~K}$ to $550 \mathrm{~K}$ ) the massflow rate does not scale exactly with pressure, but instead is reduced by an amount proportional to the square root of the temperature ratio. The faster kinetics, and the resulting higher operating frequency, may be further reducing the airflow through the combustor. The net result is that the massflow rate, at the high-pressure conditions, increased only by a factor of four for the baseline combustor, and a factor of five for the modified combustor (see Table 1) relative to the atmospheric case.

Therefore, alternative fuel injector locations and valve dynamics were investigated, with the objective to concentrate most of the fuel to the interior of the vortex, and

\begin{tabular}{|c|c|c|c|c|c|c|c|c|}
\hline \multicolumn{7}{|c|}{ Table 2. Summary of Fuel Injection and Valve Timing Events } \\
\hline $\begin{array}{c}\text { combustor } \\
\text { type }\end{array}$ & $\begin{array}{c}\text { valve } \\
\text { dynamics }\end{array}$ & figure & $\begin{array}{c}t_{\text {svo }} \\
(\mathrm{ms})\end{array}$ & $\begin{array}{c}t_{v f o} \\
(\mathrm{~ms})\end{array}$ & $\begin{array}{c}t_{s v c} \\
(\mathrm{~ms})\end{array}$ & $\begin{array}{c}t_{v f c} \\
(\mathrm{~ms})\end{array}$ & $\begin{array}{c}t_{s f i} \\
(\mathrm{~ms})\end{array}$ & $\begin{array}{c}t_{\text {efi }} \\
(\mathrm{ms})\end{array}$ \\
\hline baseline & original & Fig.1 & 1.85 & 2.44 & 3.30 & 3.72 & 1.85 & 3.72 \\
\hline baseline & original & Fig. 4 & 1.39 & 2.39 & 2.69 & 3.07 & 2.24 & 3.04 \\
\hline modified & original & Fig. 5 & 1.25 & 2.25 & 2.61 & 2.99 & 2.10 & 2.96 \\
\hline modified & reverse & Fig. 8 & 1.47 & 2.47 & 2.76 & 3.06 & 2.32 & 2.82 \\
\hline modified & reverse & Fig.12 & 1.44 & 2.44 & 2.67 & 2.97 & 2.24 & 2.84 \\
\hline modified & reverse & Fig.12 & 1.35 & 2.35 & 2.60 & 2.90 & 2.15 & 2.75 \\
\hline baseline & reverse & Fig. 13 & 1.64 & 2.64 & 3.13 & 3.43 & 2.64 & 3.14 \\
\hline baseline & reverse & Fig. 14 & 1.42 & 2.42 & 2.84 & 3.14 & 2.42 & 3.02 \\
\hline modified & reverse & Fig. 15 & 1.18 & 2.18 & 2.46 & 2.76 & 2.03 & 2.53 \\
\hline
\end{tabular}

American Institute of Aeronautics and Astronautics 
increase the massflow rate through the combustor. Initially we tested fuel injector locations inside the combustor, in order to inject the fuel directly into the vortex core. Several injector locations and fuel injection angles were tested. These configurations were unsuccessful for two main reasons. First, with the injector located inside the combustor, there was not enough time for the fuel and air to mix sufficiently prior to ignition and as a result combustion propagated too slowly and the pressure gain was very low. Secondly, the vortex location moves during the transient phase, i.e., before a limit cycle is reached, and therefore it was impossible to avoid pre-igniting the fuel due to contact between the fuel/air mixture and the combustion products.

Therefore, the idea of placing the injector inside the combustor was abandoned, and instead the injector was kept in the inlet channel with two configuration changes. First, the fuel injector was moved closer to the center of the channel, in order to direct the fuel towards the interior of the vortex (see Fig. 7b). Moving the injector to the center of the channel also creates a better air buffer zone surrounding the

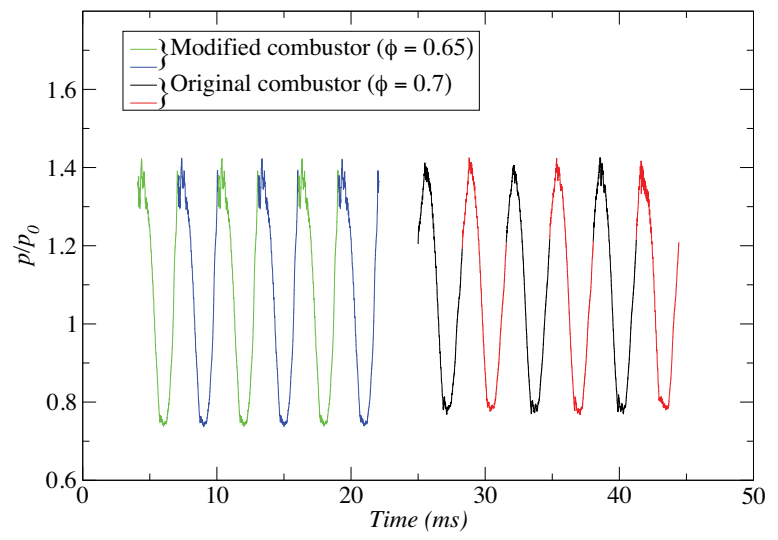

Figure 6. Pressure vs time for the baseline and modified combustors. ( $p_{0}=10$ bar, $T_{0}=$ $550 \mathrm{~K}$, Jet-A fuel). Original valve dynamics.

fuel/air mixture, slightly delaying the ignition process and improving the synchronization between the combustion process and the acoustic wave system. However, moving the injector to the center of the inlet channel forced us to reverse the valve motion, as shown in Fig. 7, in order to get the fuel into the vortex core. While the opening of the

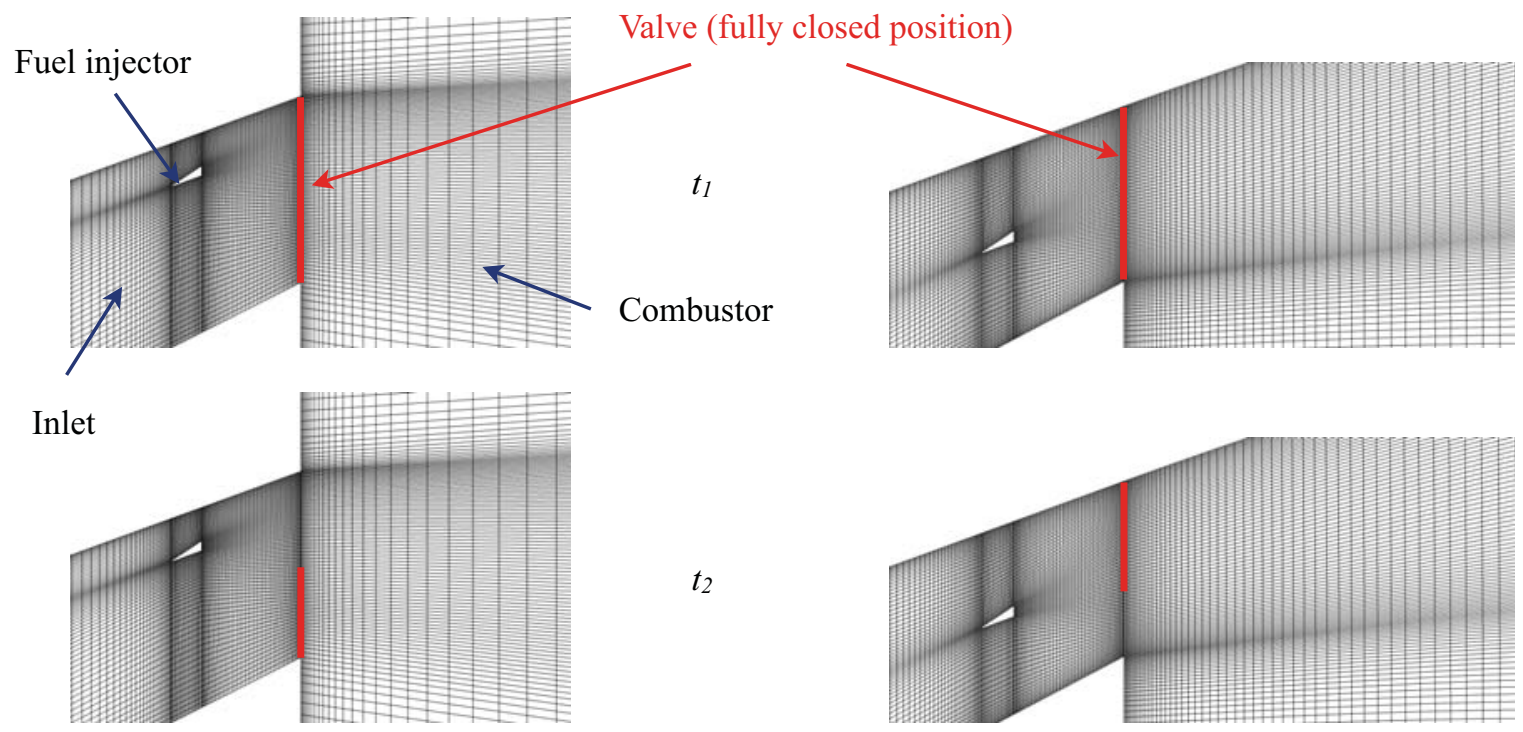

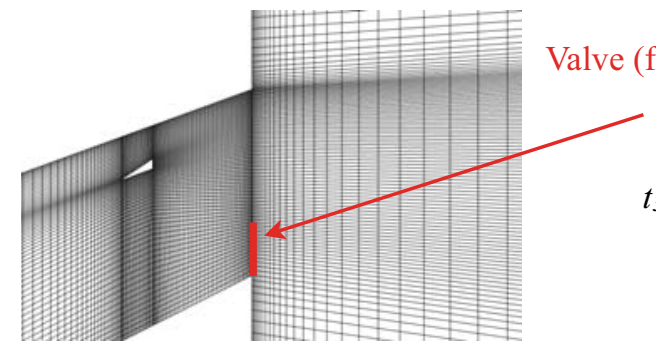

(a)

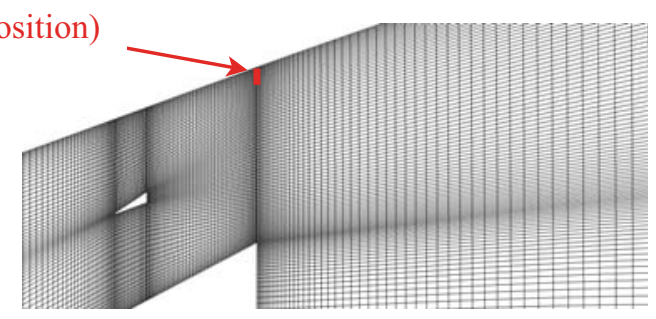

(b)

Figure 7. Schematic of valve opening action; (a) baseline combustor with original valve dynamics, (b) modified combustor with reverse valve dynamics. 


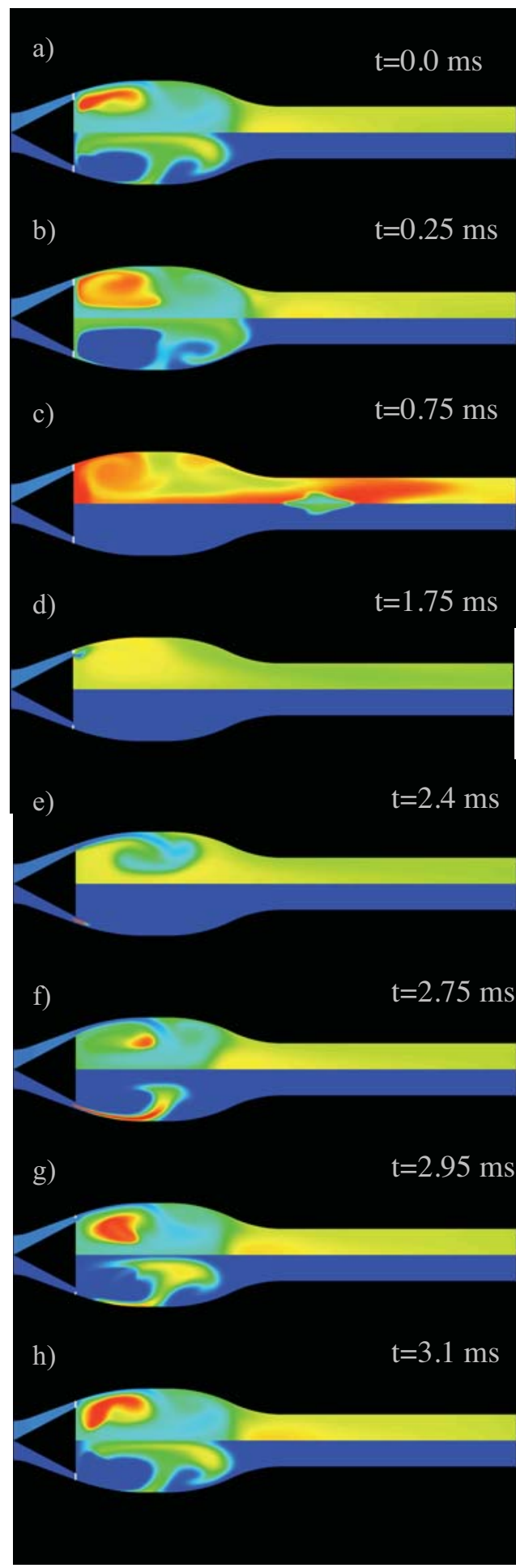

Figure 8. Nondimensional temperature contours (top half) and fuel mass fraction contours (bottom half) at various times during one cycle $\left(p_{0}=10 \mathrm{bar}, T_{0}=550 \mathrm{~K}\right.$, $\Phi=0.66)$. Modified combustor and reverse valve dynamics.

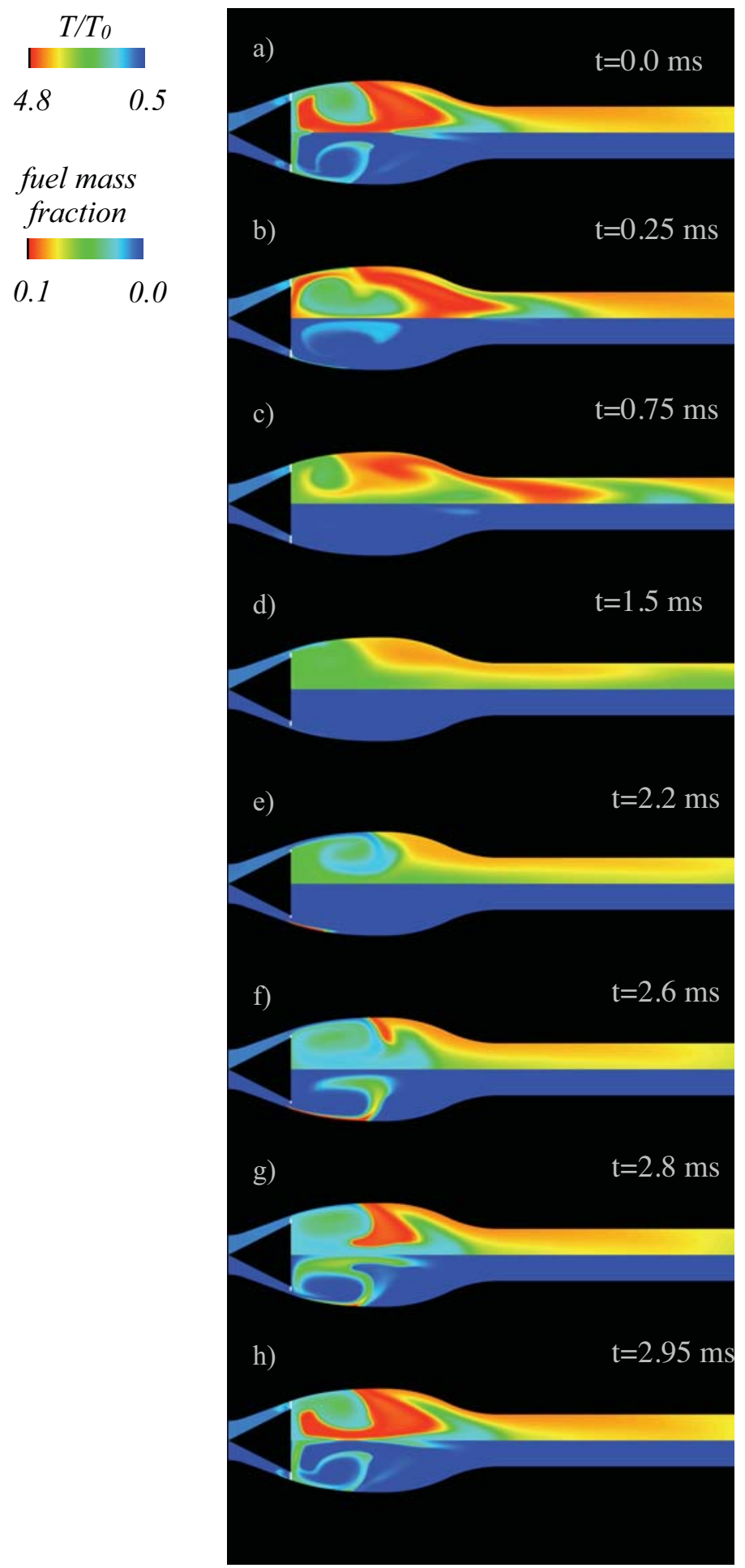

Figure 5. Nondimensional temperature contours (top half) and fuel mass fraction contours (bottom half) at various times during one cycle ( $p_{0}=10 \mathrm{bar}, T_{0}=550 \mathrm{~K}$, $\Phi=0.65)$. Modified combustor and original valve dynamics. 


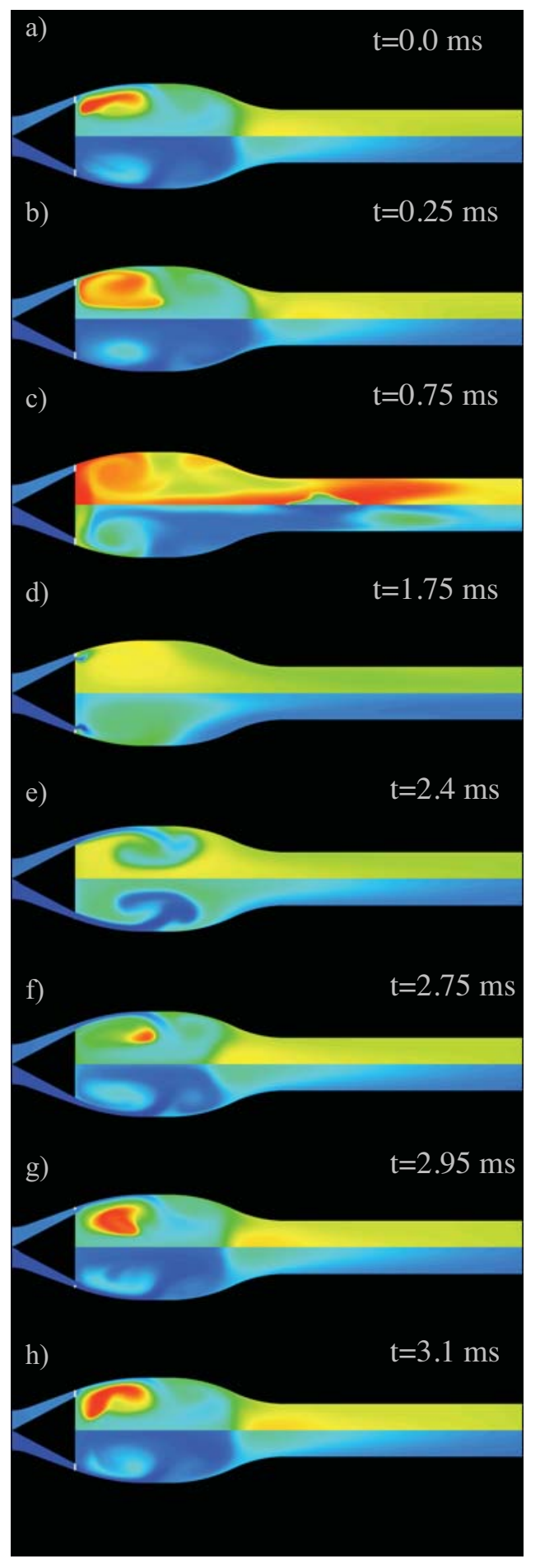

Figure 9. Nondimensional temperature contours (top half) and NO mass fraction contours (bottom half) at various times during one cycle $\left(p_{0}=10 \mathrm{bar}, T_{0}=550 \mathrm{~K}\right.$, $\Phi=0.66$ ). Modified combustor and reverse valve dynamics
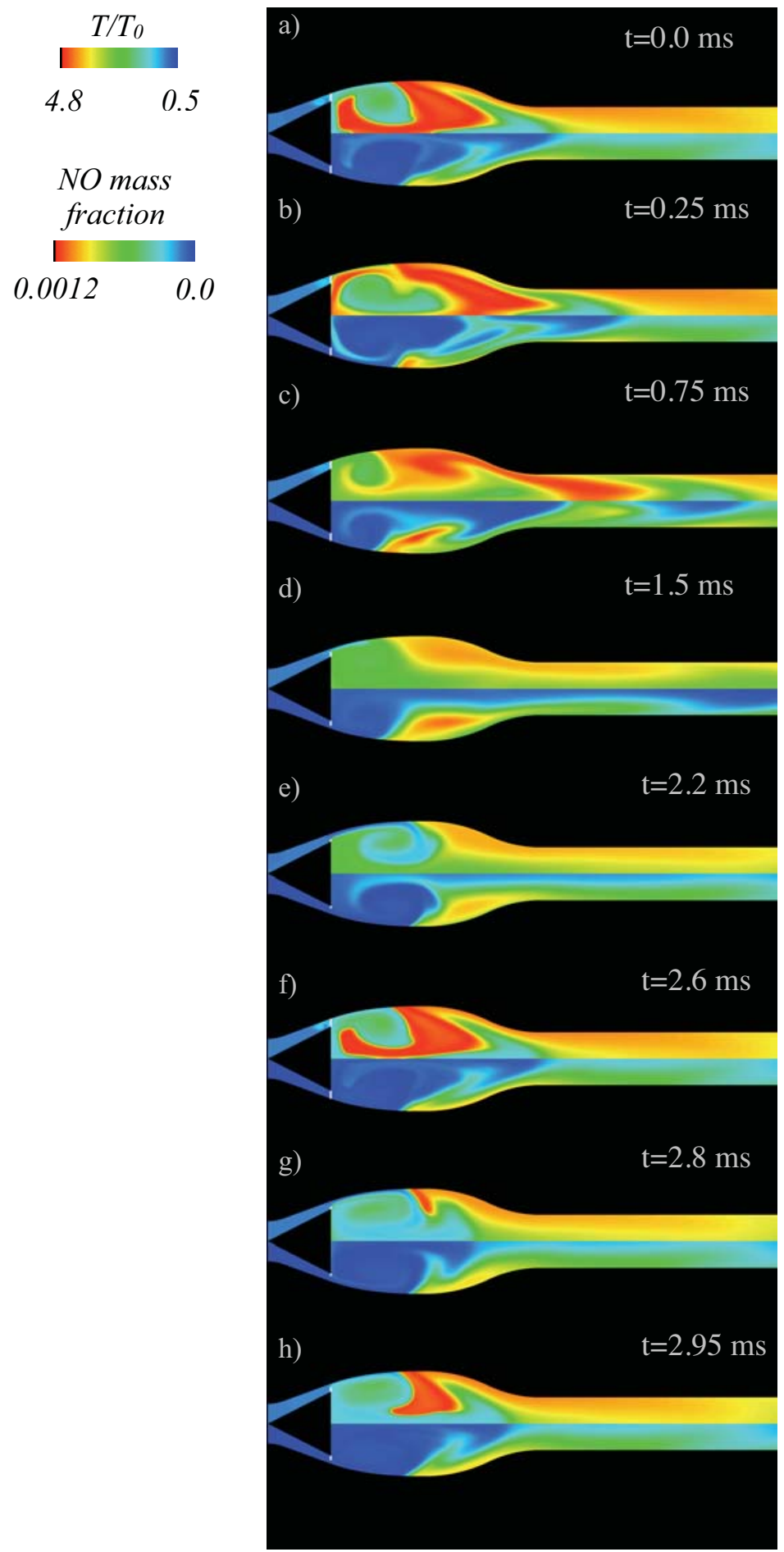

Figure 10. Nondimensional temperature contours (top half) and NO mass fraction contours (bottom half) at various times during one cycle ( $p_{0}=10 \mathrm{bar}, T_{0}=550 \mathrm{~K}$, $\Phi=0.65)$. Modified combustor and original valve dynamics. 
valve in the original configuration proceeded from top to bottom, in the new configuration the valve opens from bottom to top.

The second change involved increasing the maximum open area of the inlet to increase the airflow. In the original configuration the valve did not open to the full cross-sectional area of the inlet, as shown in Fig. 7a.This was done to match the experimental massflow rate through the combustor. The inlet area when the valve is in the fully open position is $0.73 \mathrm{in}^{2}$. In the reverse valve configuration the valve was allowed to open completely, allowing more air into the combustor. The fully open inlet area in this case is $0.87 \mathrm{in}^{2}$. The reverse valve configuration shown in Fig. $7 \mathrm{~b}$ turned out to work extremely well, as described below.

Figure 8 shows the combustion process obtained with the modified pulse-combustor and the reverse valve configuration. Figure 5 has been repeated here to allow easy comparison with the results obtained with the original valve configuration. Note the difference in the ignition characteristics of the fuel/air mixture shown in Figs. 8 and 5 . With the original valve configuration, ignition occurs at the outer edge of the vortex and the combustion front propagates around the vortex edge (Figs. $5 \mathrm{f}-5 \mathrm{~h}$ ). In the case of the reverse valve configuration, ignition occurs inside the vortex (Fig. 8f), and the combustion front remains constrained to the interior of the vortex (Figs. 8g-8h). Subsequently, the combustion propagates throughout the entire combustor (Figs. 8b, 8c).

The different combustion dynamics obtained with the reverse valve configuration also has a significant impact on the NOx production. Figures 9 and 10 show temperature contours (top half) and NO mass fraction contours (bottom half) during one cycle of operation. In the case of the original valve configuration (Fig. 10), a region of stagnant high-temperature gases ("hot-spot") is formed between the outer edge of the vortex and the combustor wall. This hightemperature region is seen to result in high levels of NO production. In the reverse valve configuration no equivalent hot-spot is present and the levels of NO produced are significantly lower.

Figure 11a shows the pressure at the head-end of the combustor for the original and reverse valve configurations. Note that the pressure amplitude is much higher for the reverse valve configuration, reaching values similar to those observed in the atmospheric case (see Table 1). The average combustor pressure ratio of 1.088 is somewhat lower than that obtained in the atmospheric case (1.158), but still better than the original high-pressure simulation. Also note that the reverse valve configuration case exhibits a period-doubling bifurcation, in which the flow repeats every other cycle. (This is visible in this plot by the alternating pressure peaks between the red and the black lines). Figure $11 \mathrm{~b}$ shows the total mass flow rate for both configurations. Note that the reverse valve configuration has a larger average mass flow rate $(0.219 \mathrm{~kg} / \mathrm{s})$ than the original valve configuration $(0.128 \mathrm{~kg} / \mathrm{s})$. Note also that for the reverse valve configuration, the mass flow rate profile repeats every other cycle, confirming the period-doubling bifurcation result.

Figure 11c compares the emission index obtained with the original and reverse valve configurations. The NOx calculations were started from the converged solution, and it takes an additional 6-8 cycles for the NOx to stabilize.
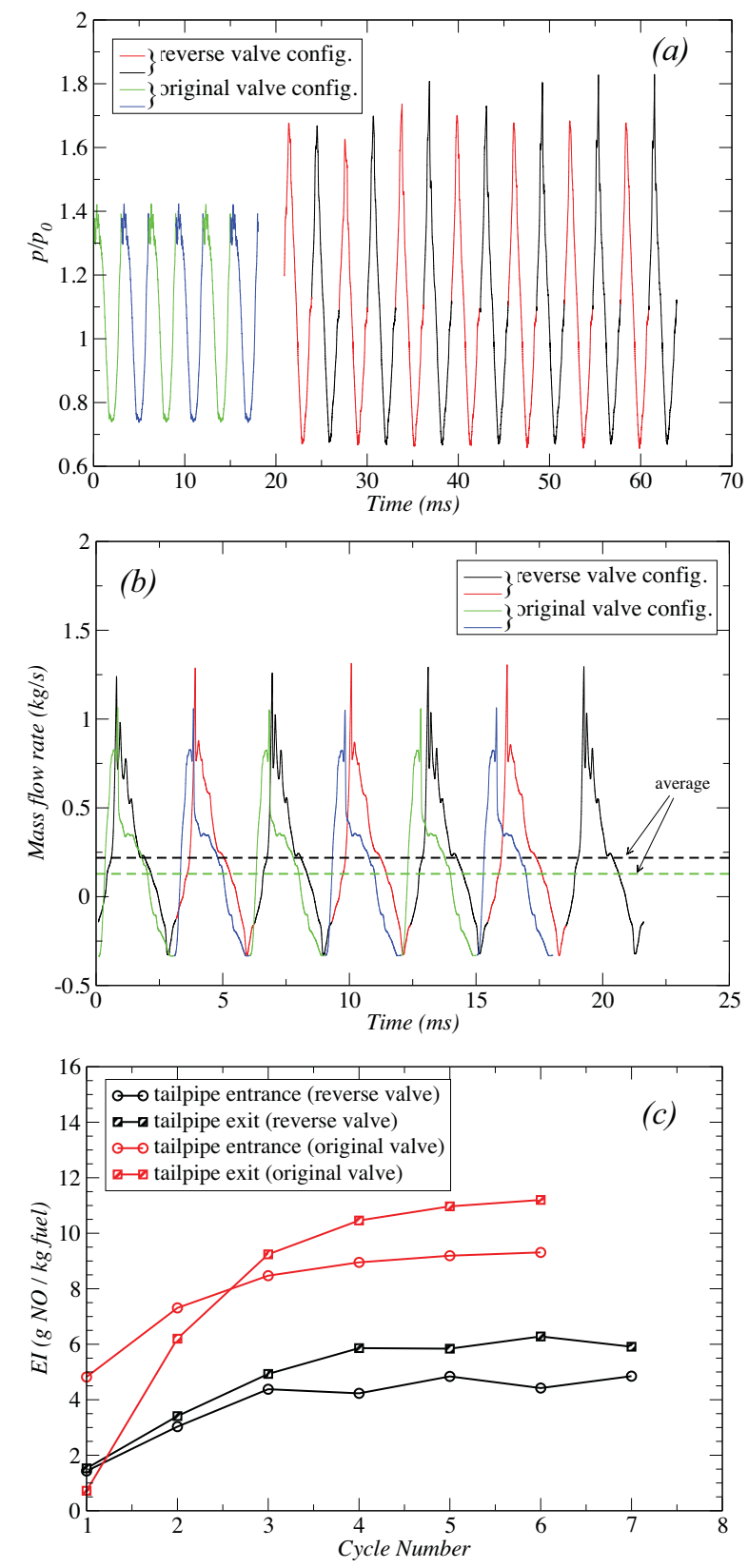

Figure 11. Comparison between original and reverse valve dynamics (modified combustor) for results shown in Figs 5 and 8. (a) Pressure vs time; (b) Total massflow rate; (c) Emission index. 

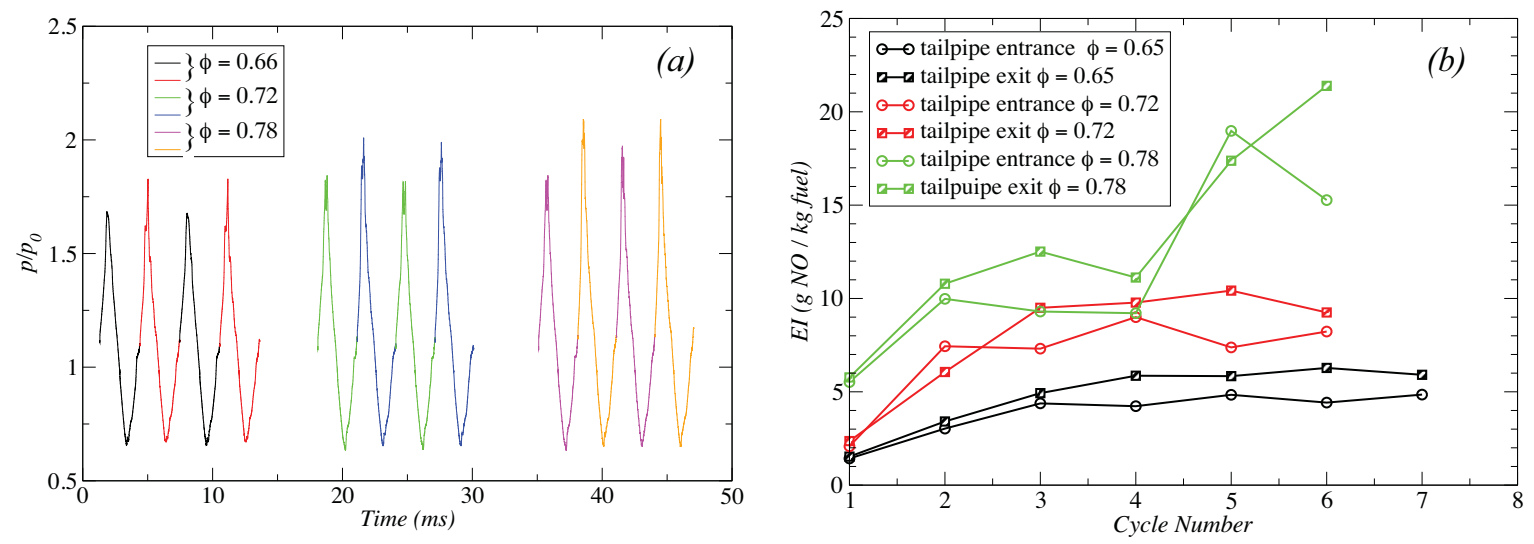

Figure 12. Pressure vs time (a) and Emission index (b) for three equivalence ratios. Modified combustor, reverse valve configuration.

This figure plots the emission index computed at the entrance and exit of the pulse-combustor tailpipe, showing that most of the NO is produced in the combustor. The results indicate that, by utilizing the reverse valve configuration, the emission index is reduced by nearly a factor of 2 . Therefore, with the reverse valve configuration we have achieved not only a higher pressure gain but also a reduction in NOx production.

Calculations were also carried out at higher equivalence ratios for the reverse valve configuration, with a slightly larger inlet area $\left(1.01 \mathrm{in}^{2)}\right.$. Figure 12 shows the pressure and emission index results for equivalence ratios of 0.66 , 0.72 and 0.78 . The plots show that the peak combustor pressure increased with equivalence ratio, reaching values higher than those observed at atmospheric conditions (see Table 1). The average combustor pressure also reached values comparable to those obtained at atmospheric conditions. As expected, the emission index increases with equivalence ratio, and the increase is larger as the mixture approaches stoichiometry. These levels of NOx emissions are comparable to those obtained with conventional gas turbine engines operating at corresponding compressor pressure ratios (see Fig. 23, in Ref. 6).

\section{(4.2) Simulation with the baseline pulse-combustor with reverse valve configuration}

Calculations were also performed with the baseline combustor and the reverse valve configuration at two equivalence ratios $(\Phi=0.57$ and $\Phi=0.64)$. The $\Phi=0.57$ case was particularly interesting since it resulted in extremely low levels of NOx.

Figure 13 shows temperature and mass fraction contours for the $\Phi=0.57$ case. The combustion process is similar to that observed with the modified combustor (Fig. 8), however, the vortex is more compact in this case. Due to the lower equivalence ratio, the temperature in the combustor is proportionately lower than that obtained in Fig.8. This lower temperature requires a longer time for ignition and thus the frequency of operation is lower ( $292 \mathrm{~Hz}$ vs $327 \mathrm{~Hz}$ ).

Figure 14 shows the pressure at the head-end of the combustor and the emission index for the two equivalence ratio cases. For the $\Phi=0.57$ case, the pressure gain is relatively low, with peak pressure ratio of 1.51 (average combustor pressure ratio of 1.052). However, the emission index for this case is extremely low. The final converged value of the emission index was $E I=0.31$. At the higher equivalence ratio $(\Phi=0.64)$, the peak and average combustor pressure ratio are higher (1.76 and 1.086 respectively) and the emission index is comparable to that obtained with the modified combustor. The emission index obtained with the $\Phi=0.57$ case is remarkably low. It is well known that the NOx reactions are relatively slow and NOx production always lags behind the temperature rise during combustion. It appears that in this case, due to the low combustion temperature, the NOx reactions did not have enough time to produce significant levels of NO before the expansion waves reflected from the exit plane reached the combustor and completely quenched any further NO production. This result is particularly interesting because it would be nearly impossible to achieve these low levels of NOx, at this equivalence ratio, with a conventional combustor. As previously mentioned, the potential for lower NOx emissions in pulse-combustors has been recognized since the earliest studies of this concept ${ }^{2}$.

\section{(4.3) Simulation with the modified pulse-combustor with reverse valve configuration at cruise conditions}

The calculations presented in the previous section (and in Ref. 6), were aimed at investigating the performance of pulse combustors at high-pressure conditions. These have been the first such calculations reported in the 

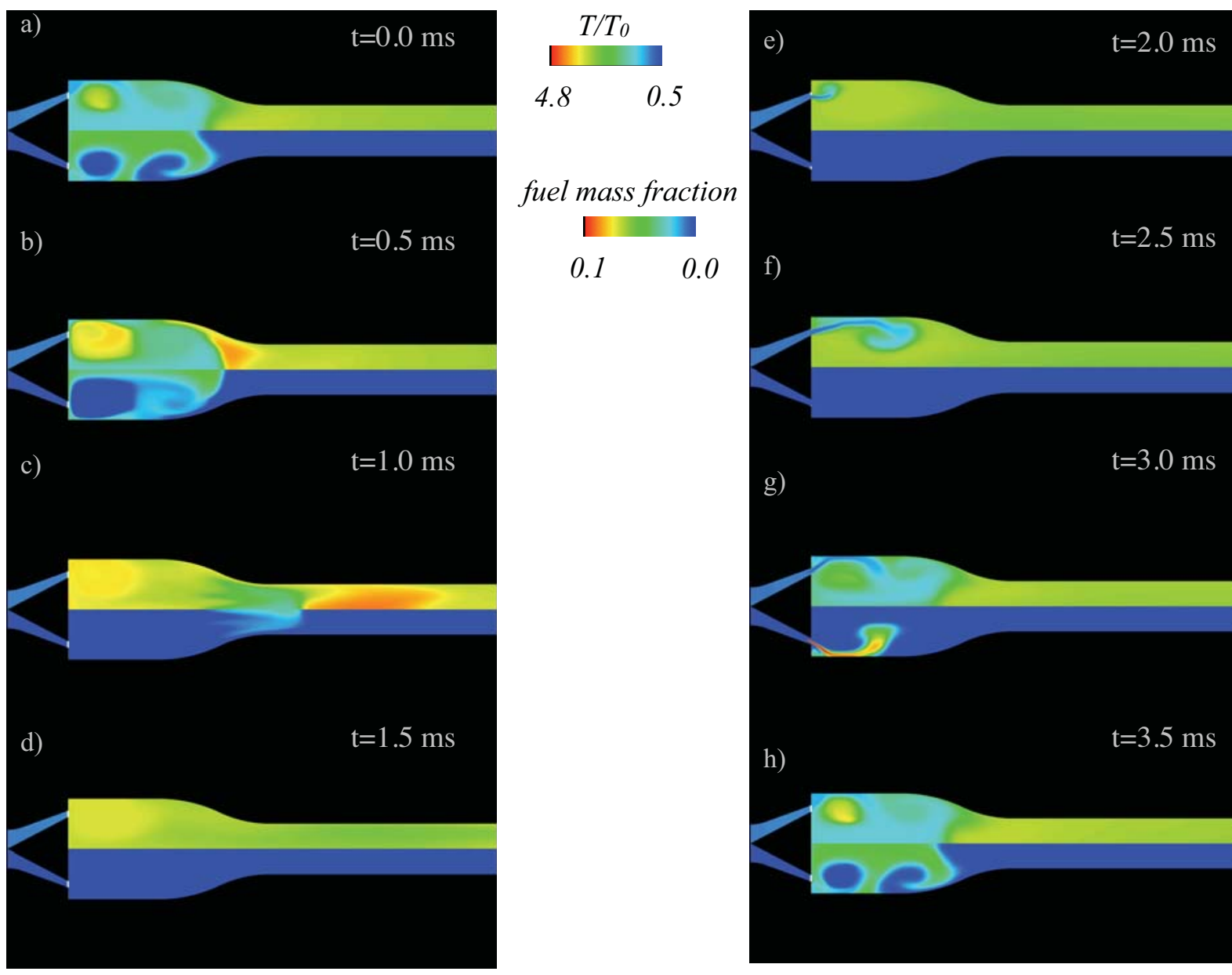

fuel mass fraction

$$
0.1 \quad 0.0
$$

$\mathrm{t}=3.0 \mathrm{~ms}$
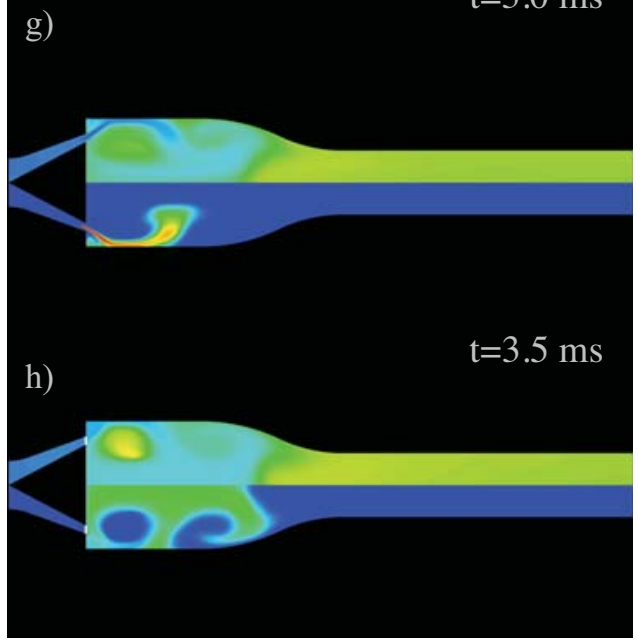

Figure 13. Nondimensional temperature contours (top half) and fuel mass fraction contours (bottom half) at various times during one cycle $\left(p_{0}=10 \mathrm{bar}, T_{0}=550 \mathrm{~K}, \Phi=0.57\right)$. Baseline combustor, reverse valve configuration.

(a)

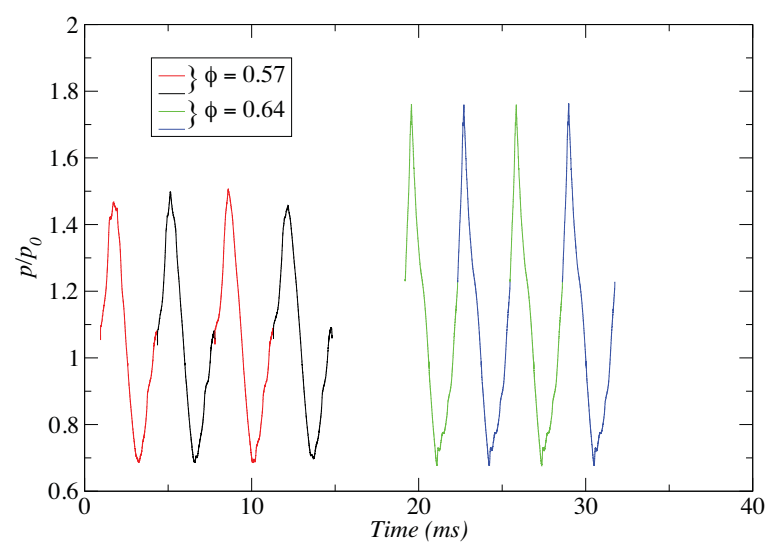

(b)

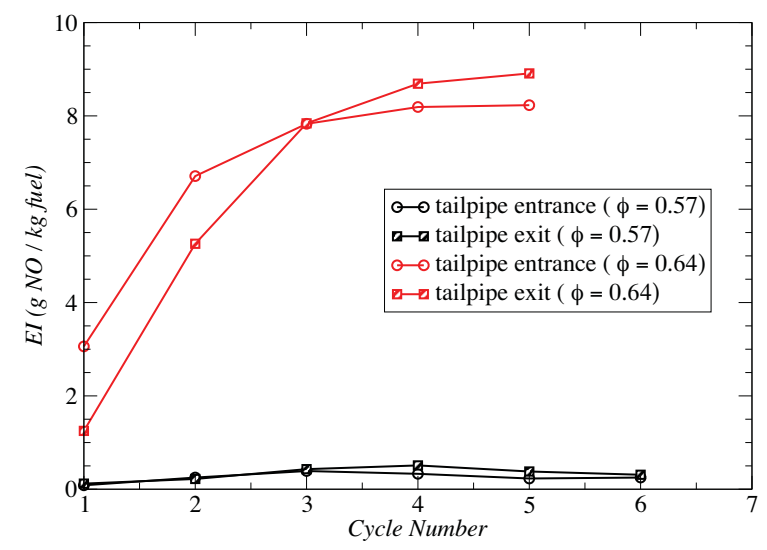

Figure 14. Pressure vs time (a) and Emission index (b) for two equivalence ratios. Baseline combustor, reverse valve configuration. 

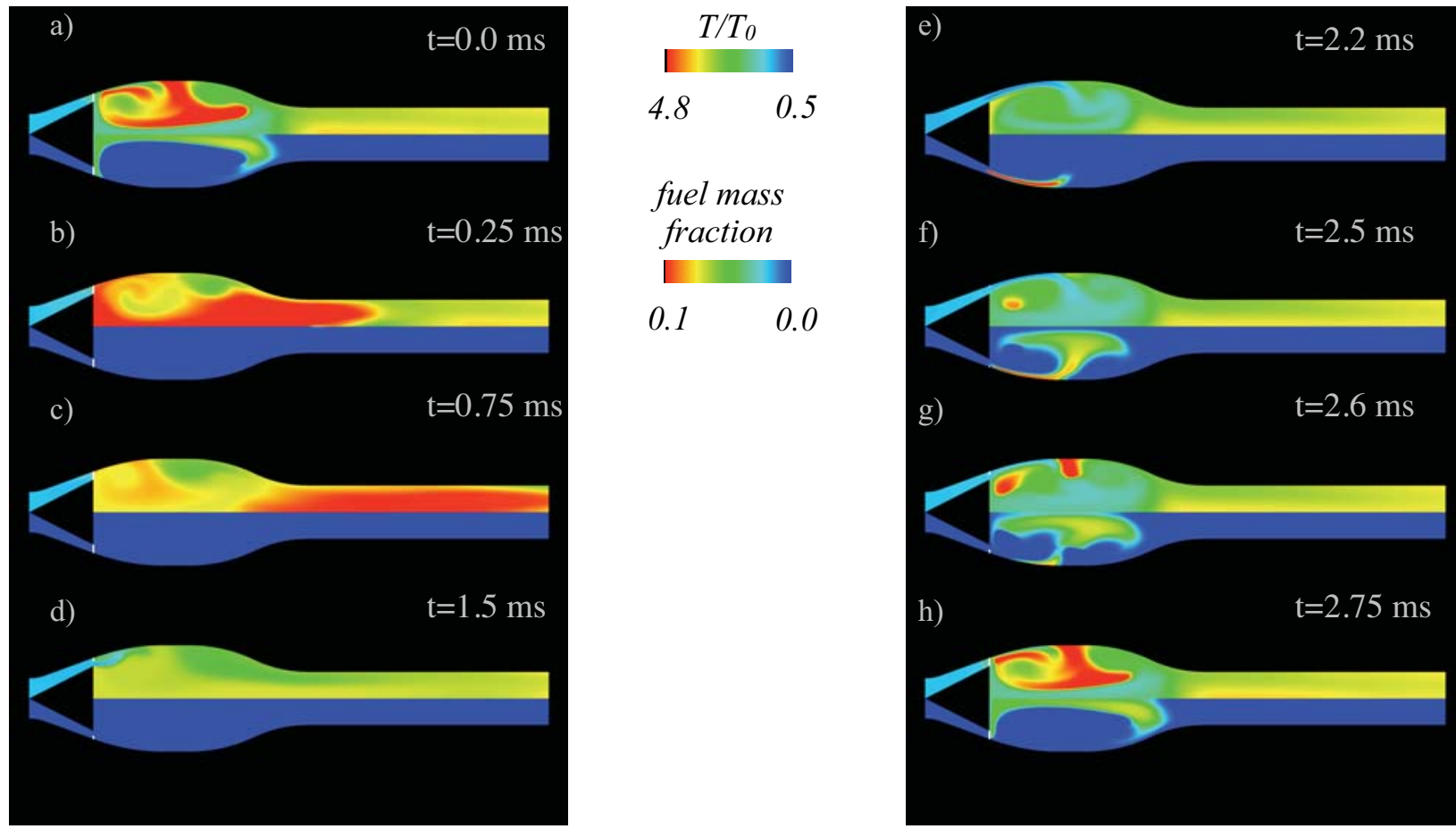

Figure 15. Nondimensional temperature contours (top half) and fuel mass fraction contours (bottom half) at various times during one cycle. Cruise conditions $\left(p_{0}=13.2 \mathrm{bar}, T_{0}=745 \mathrm{~K}\right.$, $\Phi=0.60)$. Modified combustor, reverse valve action.

literature. However, while the conditions selected $\left(p_{0}=10\right.$ bar, $\left.T_{0}=550 \mathrm{~K}\right)$ were representative of typical high pressure operation, they were not based on a specific flight condition. In this section we present a calculation for a representative cruise condition.

The simulation assumed a flight Mach number of $\mathrm{M}=0.85$ at $30000 \mathrm{ft}$ altitude, a compressor pressure ratio of 27 and a compressor efficiency of $85 \%$. These conditions resulted in a total pressure and temperature at the exit of the compressor of $p_{0}=13.2$ bar and $T_{0}=750 \mathrm{~K}$, which were used as inflow boundary conditions for the pulsecombustor. The equivalence ratio was $\Phi=0.60$. Due to the higher air temperature, operation at higher equivalence ratios was not possible with the current valve dynamics, due to substantial blowback into the inlet.

Figure 15 shows temperature and fuel mass fraction contours for the cruise condition. The higher air temperature resulted in a higher operating frequency $(362 \mathrm{~Hz})$ and also had a noticeable effect on the combustion process. Combustion starts inside the vortex (Fig. 15f) as in the previous high-pressure cases, but a secondary ignition zone also forms at the external edge of the vortex a short time later (Fig. 15g). The two combustion fronts merge subsequently (Figs 15h, 15a) and consume most of the fuel very rapidly. At $t=0.25 \mathrm{~ms}$ (Fig. 15b), most of the fuel has been burnt. Although some combustion is occurring around the edge of the vortex, this fact does not appear to affect negatively the pressure gain. Figure 16 shows the head-end pressure in the pulse-combustor. The peak pressure ratio was 1.97 and the average combustor pressure ratio was 1.082 ,both values similar to those observed in the previous high-pressure calculations. NOx calculations have not been performed yet for this case, but some negative effects due to the presence of combustion at the edge of the vortex are expected. Further studies will be needed to determine if adjustments to the fuel injection and valve dynamics could eliminate the combustion at the external edge of the vortex.

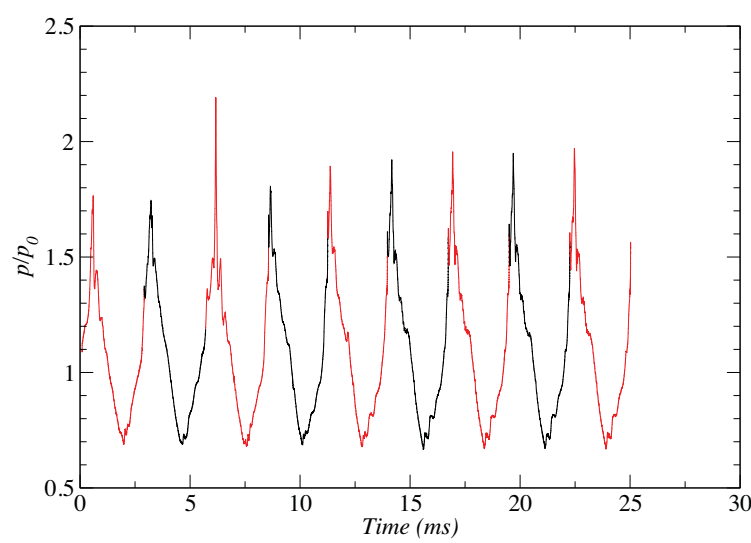

Figure 16. Pressure vs time for modified combustor and reverse valve configuration at cruise conditions. 


\section{Conclusions}

Recent numerical simulations of pulse-combustors operating at high-pressure conditions produced pressuregains significantly lower than those observed experimentally and computationally at atmospheric conditions. Two factors were identified to be limiting the pressure-gain at the high-pressure operating conditions. One was related to the location of the combustion front, which was located mainly at the external edge of the vortex, instead of being located at the the interior of the vortex, where a more efficient coupling between the combustion and the acoustic field can be achieved. The second factor was related to the reduced massflow rate through the combustor due to the higher air temperature and the higher operating frequency.

Changes to the combustor geometry, fuel injection scheme and valve dynamics were able to increase the massflow rate, and shift the combustion front back to the interior of the vortex, where it was shown to more efficiently couple with the acoustic field. These changes resulted in new pulse-combustor configurations able to achieve levels of pressure-gains comparable to those observed at atmospheric conditions. In addition, the new configurations reduced significantly the level of NOx emissions. One particular case resulted in extremely low levels of NO, producing an emission index of only 0.31 (although resulting also in a lower pressure-gain).

Calculations at representative cruise conditions demonstrated that pulse-combustors can achieve a high level of performance at such conditions.

The pulse-combustor by itself is not suitable to replace a conventional combustor in a gas turbine engine. In practical applications the pulse-combustor will have to be combined with some type of ejector device. Such pulsecombustor-ejector systems, based on the pulse-combustor configurations developed in the present study, are currently being analyzed.

\section{Appendix}

\begin{tabular}{|c|c|c|c|c|}
\hline \multicolumn{5}{|c|}{ Jet-A Reaction Mechanism (Ref. 10) ${ }^{\dagger}$} \\
\hline No. & Reaction & A & $\mathrm{n}$ & $\mathrm{E}$ \\
\hline 1 & $\mathrm{C}_{11} \mathrm{H}_{21}+\mathrm{O}_{2} \Longrightarrow 11 \mathrm{CH}+10 \mathrm{H}+\mathrm{O}_{2}$ & $1.00 \times 10^{12}$ & 0.00 & $3.75 \times 10^{4}$ \\
\hline \multicolumn{5}{|c|}{ forward $/ \mathrm{C}_{11} \mathrm{H}_{21} \quad 0.8 /$; forward $/ \mathrm{O}_{2} \quad 0.8 /$} \\
\hline 2 & $\mathrm{CH}+\mathrm{O}_{2} \Longrightarrow \mathrm{CO}+\mathrm{OH}$ & $2.00 \times 10^{15}$ & 0.00 & $3.00 \times 10^{3}$ \\
\hline 3 & $\mathrm{CH}+\mathrm{O} \Longrightarrow \mathrm{CO}+\mathrm{H}$ & $3.00 \times 10^{12}$ & 1.00 & 0.0 \\
\hline 4 & $\mathrm{H}_{2}+\mathrm{O}_{2} \Longleftrightarrow \mathrm{H}_{2} \mathrm{O}+\mathrm{O}$ & $3.98 \times 10^{11}$ & 1.00 & $4.80 \times 10^{4}$ \\
\hline 5 & $\mathrm{H}_{2}+\mathrm{O} \Longleftrightarrow \mathrm{H}+\mathrm{OH}$ & $3.00 \times 10^{14}$ & 0.00 & $6.00 \times 10^{3}$ \\
\hline 6 & $\mathrm{H}+\mathrm{O}_{2} \Longleftrightarrow \mathrm{O}+\mathrm{OH}$ & $4.00 \times 10^{14}$ & 0.00 & $1.80 \times 10^{4}$ \\
\hline 7 & $\mathrm{H}_{2} \mathrm{O}+\mathrm{O}_{2} \Longleftrightarrow \mathrm{H}_{2} \mathrm{O}+2 \mathrm{O}$ & $3.17 \times 10^{12}$ & 2.00 & $1.12 \times 10^{5}$ \\
\hline 8 & $\mathrm{CO}+\mathrm{OH} \Longleftrightarrow \mathrm{CO}_{2}+\mathrm{H}$ & $5.51 \times 10^{7}$ & 1.27 & $-7.58 \times 10^{2}$ \\
\hline 9 & $\mathrm{CO}+\mathrm{H}_{2} \mathrm{O} \Longleftrightarrow \mathrm{CO}_{2}+\mathrm{H}_{2}$ & $5.50 \times 10^{4}$ & 1.28 & $-1.00 \times 10^{3}$ \\
\hline 10 & $\mathrm{CO}+\mathrm{H}_{2}+\mathrm{O}_{2} \Longleftrightarrow \mathrm{CO}_{2}+\mathrm{H}_{2} \mathrm{O}$ & $1.60 \times 10^{14}$ & 1.60 & $1.80 \times 10^{4}$ \\
\hline
\end{tabular}




\begin{tabular}{|l|l|c|c|l|}
\hline \multicolumn{5}{|c|}{ Jet-A Reaction Mechanism (Ref. 10) } \\
\hline No. & \multicolumn{1}{|c|}{ Reaction } & $\mathrm{A}$ & $\mathrm{n}$ & \multicolumn{1}{c|}{$\mathrm{E}$} \\
\hline 11 & $\mathrm{~N}+\mathrm{N}+\mathrm{M} \Longleftrightarrow \mathrm{N}_{2}+\mathrm{M}$ & $2.80 \times 10^{17}$ & -0.75 & 0.0 \\
\hline 12 & $\mathrm{~N}+\mathrm{O}_{2} \Longleftrightarrow \mathrm{NO}+\mathrm{O}$ & $6.40 \times 10^{9}$ & 1.00 & $6.30 \times 10^{3}$ \\
\hline 13 & $\mathrm{~N}+\mathrm{NO} \Longleftrightarrow \mathrm{N}_{2}+\mathrm{O}$ & $1.60 \times 10^{13}$ & 0.00 & 0.0 \\
\hline 14 & $\mathrm{~N}+\mathrm{OH} \Longleftrightarrow \mathrm{NO}+\mathrm{H}$ & $6.30 \times 10^{11}$ & 0.50 & 0.0 \\
\hline $\begin{array}{l}{ }^{\dagger} \text { Forward rate coefficient } k_{f}=A T^{b} e^{-(E / R T)} ; \text { units are moles, seconds, centimeters, calories and } \\
\text { Kelvins. }\end{array}$ \\
\hline
\end{tabular}

\section{Acknowledgments}

This study was supported by NASA under NRA grant number NNC08TA48T. The computational resources were provided by the NASA Advanced Supercomputing (NAS) Division.

\section{References}

1. Paxson, D.E. and Dougherty, K., "Ejector Enhanced Pulsejet Based Pressure Gain Combustors: An Old Idea With a New Twist," AIAA paper 2005-4216, July 2005.

2. Keller, J.O. and Bramlette, T.T., "Pulse Combustion: The Importance of Characteristic Times," Combustion and Flame, 75, 33-44 (1989).

3. Geng, T., Kiker Jr, A., Ordon, R., Kuznetsov, A.V., Zeng, F. and Roberts, W.L., "Combined Numerical and Experimental Investigation of a Hobby-Scale Pulsejet," Journal of Propulsion and Power, Vol. 23, No. 1, 2007.

4. Geng, T., Zheng, F., Kuznetsov, A. V., Roberts, W. L., Paxson, D. E., "Comparison Between Numerically Simulated and Experimentally Measured Flowfield Quantities Behind a Pulsejet, Flow," Turbulence and Combustion, Vol. 84, No. 4, pp. 653-667, May 2010.

5. Putman, A.A., Belles, F.E., and Kentfield, J.A.C., "Pulsed Combustion," Progress in Energy and Combustion Science, Vol. 12, 1, 1986, pp. 43-79.

6. Yungster, S., Paxson, D.E. and Perkins, H.D.," Computational Study of Pulsejet-Driven Pressure Gain Combustors at High-Pressure," AIAA paper 2013-3709, July 2013.

7. Yungster, S. and Radhakrishnan, K., A Fully Implicit Time Accurate Method for Hypersonic Combustion: Application to Shock-Induced Combustion Instability. Shock Waves, 5, 293-303, (1996).

8. Yungster, S. and Radhakrishnan, K., Pulsating one-dimensional detonations in hydrogen-air mixtures. Combustion Theory and Modeling, 8, 745-770, (2004).

9. Spalart, P. R. and Allmaras, S. R., A One-Equation Turbulence Model for Aerodynamic Flows, La Recherche Aerospatiale, 1, 5-21, (1994).

10. Ajmani, K., Kundu, K. and Penko, P.F., "A Study on Detonation of Jet-A Using a Reduced Mechanism," AIAA paper 2010-1515, January 2010.

11. Ajmani, K., Mongia, H.C. and Lee, P., "Evaluation of CFD Best Practices for Combustor Design: PART II Reacting Flows", AIAA Paper 2013-1143, Jan. 2013.

12. Jachimowski, C.J., An Analytical Study of the Hydrogen-Air Reaction Mechanism with Application to Scramjet Combustion. NASA TP-2791, (1988).

13. Yungster, S., Radhakrishnan, K. and Breisacher, K., Computational Study of NOx Formation in HydrogenFueled Pulse Detonation Engines,' Combustion Theory and Modeling, 10, 981-1002, (2006).

14. Yungster, S., and Breisacher, K., "Study of NOx Formation in Hydrocarbon-Fueled Pulse Detonation Engines," AIAA paper 2005-4210, 2005. 